\title{
Sunflower consortium with cowpea productive performance in underground dam with irrigation supplementary
}

\section{Anderson Ramos de Oliveira ${ }^{1}$, Roseli Freire de Melo $^{2}$, João Marcos Rodrigues dos Santos ${ }^{3}$}

\author{
${ }^{1,2}$ Embrapa Semiárido. BR-428, Km 152, Zona Rural - Caixa Postal 23. Petrolina-PE.
}

${ }^{3}$ Universidade de Pernambuco. BR 203, Km 2, s/n - Petrolina-PE.

Email:anderson.oliveira@embrapa.br ,roseli.melo@embrapa.br, joaorodriguesestagio.embrapa@gmail.com

Received: February $11^{\text {th }}, 2017$

Accepted: March $17^{\text {th }}, 2017$

Published: June $30^{\text {th }}, 2017$

Copyright $\bigcirc 2016$ by authors and Institute of Technology Galileo of Amazon (ITEGAM). This work is licensed under the Creative Commons Attribution International License (CC BY 4.0).

http://creativecommons.org/lic enses/by/4.0/ (c) (i) (2) Open Acet:

\section{ABSTRACT}

The semiarid region characterized by low rainfall and the precipitation irregularity. In these environments, capture and rainwater storage technologies should be adopted to allow cultivation. Among the existing technologies, the underground dampresents with great potential to promote the maintenance of moisture in the soil and allow the cultivation for a longer period. Coupled with the underground dam, supplemental irrigation can be an alternative, es pecially for those periods of extreme shortage. Among thecrops managed under these conditions sunflower and cowpea are characterized by relative tolerancetodroughtstress. Thus, this study aimed to evaluate the performance of sunflower intercropped with cowpea when grown in underground damin the semiarid region, prolonged dry seas on with water supplementation. Theexperiment was conducted in underground dam located in the production field Embrapa Produtos e Mercados, in Petrolina, PE, Brazil. The experimental design was a randomized block with two treatments: single sunflower (Helio 251 cultivar) and sunflower intercropped with cowpea (BRS Guariba cultivar) in four blocks. At 95 days after planting were as ses sed the following parameters: plant height, stem diameter,head diameter, thous and grain biomass and productivity. The height reached by sunflowerplants inintercropping system was lower than in single crop. The stemdiameter, the chapter diameter and biomass of 1,000grains showed no difference between the two cropping systems. The cultivation of sunflower intercropped with cowpea in underground dam, with supplemental irrigation has lower productivity by sunflower monoculture.

Keywords: Consortium; Helianthus annuus L.; Vigna unguiculata (L.) Walp; semiarid.

\section{Desempenho produtivo de girassol consorciado com feijão-caupi em barragem subterrânea com irrigação suplementar}

RESUMO

A região semiárida caracteriza-se pela escassezde chuvas e pela irregularidade de precipitação. Nestes ambientes, devem ser adotadas tecnologias de captação e armazenamento de água de chuva a fim de pos sibilitar o cultivo. Dentre as tecnologias existentes, a barragemsubterrânea apresenta-se comgrande potencial para promover a manutenção da umidade no solo e permitir o cultivo por período mais prolongado. Aliada à barragem subterrânea, a irrigação suplementar pode ser uma alternativa, principalmente para aqueles períodos de extrema escassez. Dentre as culturas manejadas nestascondições o giras sole o feijão-caupi se des tacampela relativa tolerância ao es tres se hídrico. Assim, es tetrabalhoteve como objetivo avaliar o des empenho produtivo de giras sol cons orciado comfeijão -caupiquandocultivado em barragem subterrânea na região semiárida, em período de estiagem prolongada comsuplementação hídrica. $\mathrm{O}$ experimento foi conduzido em barragem subterrânea localizada no campo de produção pertencente à Embrapa Produtos e Mercados, emPetrolina, PE. O delineament o experimental adotado foi em blocos casualizados, com dois tratamentos: giras sol solteiro (Hélio 251) e giras sol consorciado com feijão-caupi (BRS Guariba), em quatro blocos. Aos 95 dias após o plantio foram avaliados os seguintes parâmetros: altura da planta, diâmetro do caule, diâmetro do capítulo, biomassa de mil grãos e produtividade. A altura alcançada pelas plantas de giras solems is tema consorciado foi inferior ao cultivo em solteiro. As análises de diâmetro do caule, diâmetro do capítulo e biomassa de 1.000 grãos não demonstraram diferenças entre os dois sis temas de cultivo. O cultivo do giras sol cons orciado comofeijãocaupi, em barragem subterrânea, com irrigação suplementar apresenta produtividade inferior ao monocultivo do girassol.

Palavra-Chave: Consórcio; Helianthus annuus L.; Vigna unguiculata (L.) Walp; semiárido. 


\section{INTRODUÇÃO}

A região semiárida brasileira é caracterizada, principalmente, por apresentar baixos índices pluviométricos e elevadas temperaturas durante todo o ano. De acordo com [1], o Semiárido brasileiro apresenta condições insuficientes de reservas hídricas em seus mananciais para atender à demanda, devido à escassez de chuvas, aliada à irregularidade e à concentração de precipitação em curtos períodos do ano, em geral em poucos meses. Este quadro climático é agravado pelas altas temperaturas e forte insolação. Nestas condições de restrição hídrica, os agricultores devem buscar alternativas de captação, armazenamento e manejo de água da chuva, a fim de amenizar os prejuízos causados por estiagens prolongadas. Dentre as tecnologias desenvolvidas para armazenamento de água de chuva, a barragem subterrânea destaca-se por permitir que a área cultivada mantenha níveis de umidade mais elevados do que as áreas circunvizinhas e, consequentemente, contribua para a prática agrícola ao disponibilizar água para os cultivos, mesmo que por curto período.

Segundo [2], a tecnologia utilizada na barragem subterrânea, parte do princípio de que que a construção transversal de um septo impermeável à direção do fluxo das águas em uma microbacia, possibilitará a manutenção da água no subsolo por período prolongado, permitindo que área seja explorada num sistema de agricultura de vazante e/ou subirrigação. A diversificação de cultivos nestes ambientes é potencializada, uma vez que culturas que sejam tolerantes ao estresse hídrico e outras com menor tolerância serão favorecidas pela umidade presente no subsolo. Assim, o cultivo de oleaginosas, como o girassol, pode apresentar maior possibilidade de sucesso.

O girassol (Helianthus annuus L.), por apresentar boa tolerância à seca e ao calor, tornar-se uma importante alternativa para o semiárido brasileiro. Como tal região não dispõe de boa infraestrutura agrícola, e a maioria da população sobrevive por meio de atividades ligadas à agricultura familiar, o plantio de oleaginosas pode contribuir para incrementar a renda e estimular a permanência da população nas áreas rurais. Em trabalho realizado por [3], em região semiárida, com o objetivo de avaliar caracterís ticas de desenvolvimento da cultura, concluiu-se que o girassol desenvolve-se satisfatoriamente na região semiárida, podendo seu cultivo ser recomendado como mais uma alternativa para o setor produtivo nesta região.
Devido à crescente demanda do setor industrial e comercial, a cultura do girassol está se tornando importante opção econômica no sis tema de rotação, consórcio e sucessão de culturas nas regiões produtoras de grãos [4]. Toda esta demanda foi favorecida pela corrida por fontes alternativas de combustível e pelos incentivos governamentais baseados no Programa Nacional de Produção e Uso de Biodiesel. De acordo [5], o rendimento emóleo e o uso de terra por tonelada de óleo produzida são indicadores de grande importância a serem considerados no programa governamental para avaliação de viabilidade econômica, social e ambiental.

Dentro deste contexto o girassol é vis to como uma das principais culturas para obtenção de óleos vegetais combustíveis no Brasil. Sabe-se que os grãos de giras sol são bastante ricos em óleo, podendo apresentar teores variáveis, os quais dependemda cultivar e da época de plantio [6]. Devido ao seu teor de óleo e às excelentes características físico-químicas do óleo, o girassol pode ser utilizado para a produção de biodiesel, apresentando viabilidade técnico-ambiental na produção de biocombustíveis . Estudo realizado por [7] demons trou que a produção de biodiesel etílico a partir do óleo bruto de girassol é possível, possuindo o biocombustível obtido pelo processo de transesterificação de tal óleo características apropriadas para utilização em motores a diesel.

Assim, este trabalho teve como objetivo avaliar o desempenho produtivo de giras sol consorciado comfeijão-caupi quando cultivado em barragem subterrânea na região semiárida, em período de estiagem prolongada com suplementação hídrica.

\section{MATERIAIS E MÉTODOS}

O experimento foi conduzido em barragem subterrânea localizada no campo de produção pertencente à Embrapa Produtos e Mercados, em Petrolina, PE. O solo da área experimental foi classificado como Latossolo Vermelho Amarelo, com textura média. Previamente ao plantio, foi realizado o preparo da área por meio de uma aração na camada de $20 \mathrm{~cm}$, seguida de gradagem, a fim de uniformizar e nivelar o terreno. Realizou-se também a amostragem de solo na profundidade de $0-20 \mathrm{~cm}$, sendo as amostras conduzidas para o Laboratório de Solos e Água da Embrapa Semiárido, onde foram submetidas à análise química, conforme metodologia proposta pela [8]. A tabela 1 apresenta o resultado da análise química.

Tabela 1. Características químicas do solo na barragem subterrânea, Petrolina-PE.

\begin{tabular}{|c|c|c|c|c|c|c|c|c|c|c|c|c|c|}
\hline \multirow{2}{*}{$\begin{array}{l}\text { Prof } \\
\text { (cm) }\end{array}$} & pH & $\mathbf{P}$ & $\mathbf{K}$ & $\mathrm{Ca}^{2+}$ & $\mathrm{Mg}^{2+}$ & $\mathbf{A l}^{3+}$ & $\mathbf{H}+\mathrm{Al}^{3+}$ & $\mathrm{Na}^{+}$ & $\mathbf{S}($ base $)$ & CTC & V & CE & MO \\
\hline & $\mathrm{H}_{2} \mathrm{O}$ & $\mathrm{mg} / \mathrm{dm}^{3}$ & \multicolumn{8}{|c|}{$\mathrm{Cmol}_{\mathrm{c}} \mathrm{dm}^{-3}$} & $\%$ & $\mathrm{dS} \mathrm{m}^{-1}$ & $\mathrm{~g} \mathrm{~kg}^{-1}$ \\
\hline $0-20$ & 5,0 & 2,91 & 0,32 & 1,0 & 0,5 & 0,0 & 5,0 & 0,05 & 1,9 & 6,8 & 27,4 & 0,79 & 2,9 \\
\hline
\end{tabular}

De acordo com a classificação de Köppen, a região semiárida enquadra-se no tipo BSwh, caracterizada por balanço hídrico negativo, com médias inferiores a $650 \mathrm{~mm}$ anuais, temperaturas médias elevadas de $23^{\circ}$ a $27^{\circ} \mathrm{C}$, insolação média de $2.800 \mathrm{~h}^{2} o^{-1}$, evaporação de $2.000 \mathrm{~mm} \mathrm{ano}^{-1}$ e umidade relativa do ar média de $55 \%$. Durante o período experimental, monitoraram- se as condições climáticas na Estação Agrometeorológica da Caatinga, da Embrapa Semiárido, sendo os dados médios de temperatura máxima de 33,0C, temperatura mínima de 20,8C, e temperatura média de 26,8C, umidade relativa média de 50,9\%, evapotranspiração de referência de $5,25 \mathrm{~mm}$ e zero de precipitação. 
O delineamento experimental adotado foi em blocos casualizados, com dois tratamentos: girassol solteiro e girassol consorciado com feijão-caupi, em quatro blocos. Utilizou-se a cultivar de girassol Hélio 251 (H251) que é um híbrido simples com aquênios de cor estriada e a cultivar de feijão-caupi BRS Guariba. Cada parcela consorciada foi composta por quatro linhas de girassol alternadas com quatro linhas de feijão-caupi, ambas as culturas foram cultivadas em linhas com cinco metros de comprimento. A parcela do girassol em regime de cultivo em solteiro foi composta por quatro linhas. Para as avaliações, foram selecionadas seis plantas por parcela, sendo as mesmas coletadas aleatoriamente na área útil (duas linhas centrais de girassol, desprezando-se um metro nas extremidades).

O espaçamento adotado foi de 0,30 m entre plantas e 0,80 m entre linhas, tanto para o girassol, quanto para o feijão-caupi, perfazendo uma população de aproximadamente 41.000 plantas por hectare. O plantio foi realizado em agosto de 2015. Para que não ocorressem perdas no estande de plantas devido à estiagem prolongada, utilizou-se a irrigação suplementar, sendo esta aplicada via sistema de gotejamento, com gotejadores espaçados em $0,50 \mathrm{~m}$. A irrigação foi baseada no mínimo necessário para que a cultura pudesse produzir grãos. Assim, considerou-se uma irrigação suplementar, baseada em Castro \& Farias (2005), de até $400 \mathrm{~mm}$ distribuída ao longo do ciclo.

Aos 95 dias após o plantio, foram avaliados os seguintes parâmetros: altura da planta, diâmetro do caule, diâmetro do capítulo, biomassa de mil grãos e produtividade. Para a altura da planta, foi considerada a distância entre a superfície do solo e a inserção do capítulo, quando este atingiu o ponto de maturação fisiológica. Para o diâmetro do caule, considerou-se a média de três medidas observadas aos $5,0 \mathrm{~cm}$ de distância do solo. Após o corte das plantas úteis, mediu-se o diâmetro dos capítulos com o auxílio de uma fita métrica; os capítulos foram colocados emsacos e levados para a secagem ao sol, Após secagem, os grãos dos capítulos de cada parcela foram pesados para obtenção da biomassa de 1.000 grãos e estimativa da produtividade em toneladas por hectare.

Os dados foram submetidos à análise de variância e as médias foram comparadas pelo teste de Tukey a $5 \%$ de probabilidade, utilizando-se o programa Sisvar versão 5.6 [9].

\section{RESULTADOS E DISCUSSÃO}

A altura alcançada pelas plantas de girassol em sistema consorciado, aos 95 dias após o plantio, foi inferior ao cultivo em solteiro, conforme as médias apresentadas na Tabela 2. Esta redução na altura das plantas consorciadas pode estar relacionada à presença do feijão-caupi, pois as espécies podemter estabelecido uma relação de competição por água, nutrientes e luz.

Tabela 2. Biometria de plantas de girassol cultivadas em regime de solteiro e em regime de consórcio em barragem subterrânea, Petrolina, PE.

\begin{tabular}{lccccc}
\hline \multicolumn{1}{c}{ Tratamento } & $\begin{array}{c}\text { Altura } \\
(\mathrm{m})\end{array}$ & $\begin{array}{c}\text { Diâmetro do } \\
\text { Caule }(\mathrm{mm})\end{array}$ & $\begin{array}{c}\text { Diâmetro do } \\
\text { Capítulo }(\mathrm{mm})\end{array}$ & $\begin{array}{c}\text { Biomassa de } \\
1.000 \mathrm{grãos}(\mathrm{g})\end{array}$ & $\begin{array}{c}\text { Produtividade } \\
(\mathrm{kg} \mathrm{ha})\end{array}$ \\
\hline Cultivo solteiro & $1,56 \mathrm{a}$ & $24,70 \mathrm{a}$ & $112,52 \mathrm{a}$ & $50,50 \mathrm{a}$ & $1.627,67 \mathrm{a}$ \\
Cultivo consorciado & $1,46 \mathrm{~b}$ & $21,90 \mathrm{a}$ & $108,09 \mathrm{a}$ & $48,20 \mathrm{a}$ & $1.467,12 \mathrm{~b}$ \\
\hline C.V. $(\%)$ & 10,92 & 21,64 & 12,15 & 8,41 & 9,09 \\
\hline D.M.S. & 0,096 & 2,947 & 7,831 & 2,426 & 82,198 \\
\hline
\end{tabular}

* Médias seguidas por letras diferentes, na coluna, diferem entre si pelo teste de Tukey a $5 \%$ de probabilidade.

Fonte: Autores, (2016).

Considerando-se o sistema com limitação hídrica, é provável que a maior competição tenha sido por água, uma vez que durante todo o período experimental não houve precipitação e que nos dois meses anteriores ao plantio (junho e julho) houve precipitação acumulada de apenas $14 \mathrm{~mm}$. Assim, a disponibilidade hídrica existente no solo se deveu apenas à irrigação suplementar e à capacidade da barragem subterrânea em acumular água. Diferenças na altura de plantas em cultivos solteiro e consorciado também foram observadas por [10] em região semiárida da Etiópia. Contudo, [11] avaliando a cultivar Catissol, não verificou diferenças em altura entre as plantas consorciadas com o feijão-caupi e àquelas cultivadas em solteiro.

As análises de diâmetro do caule, diâmetro do capítulo e biomassa de 1.000 grãos não demonstraram diferenças entre os dois sistemas de cultivo. O diâmetro médio do caule das plantas de girassol foi de $23,3 \mathrm{~mm}$.

Em relação ao diâmetro do capítulo, verificou-se média de $110,30 \mathrm{~mm}$, assemelhando-se ao resultado encontrado por [12], que ao estudarem a cultivar H251 cultivada sem irrigação, observaram diâmetro médio do capítulo das plantas de 122,0 mm. Para [13], avaliando esta mesma cultivar, encontraram valor médio de diâmetro do capítulo um pouco maior $(174,65$ $\mathrm{mm})$. O diâmetro do capítulo é uma característica importante na avaliação do girassol, pois nele são encontradas as flores que darão origem aos futuros grãos. De acordo com [14], cada capítulo apresenta em média de 6 até $50 \mathrm{~cm}$ de diâmetro, sendo comumente encontrado um número de 800 a 1.700 flores por capítulo.

A biomassa de 1.000 grãos também não diferiu entre os tratamentos. Os valores apresentados são maiores do que o encontrado por [2] para a cultivar H251que foi de 35,61g.

A produtividade do sistema de solteiro foi superior ao sistema de consórcio. As diferenças, as sim como a diferença em altura de plantas, podem estar relacionadas à competição pelos fatores essenciais para o desenvolvimento da planta. Os resultados corroboram com [11] que também constataram que o sistema de consorciação casou reduções na produtividade do girassol e feijão caupi em comparação ao monocultivo.

Tanto a produtividade do girassol cultivado solteiro, quanto do girassol cultivado consorciado foram inferiores à produtividade alcançada por [2] que notaram produtividade média de $1.924,27 \mathrm{~kg} \mathrm{ha}^{-1}$ em sistema de sequeiro e de $2.863,12$ $\mathrm{kg} \mathrm{ha}^{-1}$ em condições irrigadas utilizando-se lâmina de 522,14 
mm. Contudo, as produtividades alcançadas são superiores à média nacional para a cultura do girassol que atualmente é estimada em $1.250 \mathrm{~kg} \mathrm{ha}^{-1}$ [15], devendo-se enfatizar o fato de que o cultivo em barragem subterrânea utilizando apenas irrigação suplementar é um diferencial, pois a barragem auxilia na manutenção da umidade.

Esse resultado reforça as informações de [16] sobre o bom rendimento do girassol em disponibilidades hídricas de 400 a $500 \mathrm{~mm}$ bem distribuídas durante o ciclo da cultura, o que também estaria em consonância com as informações sobre a evapotranspiração da cultura, uma vez que [17], informam que a evapotranspiração total da cultura (ETc) do girassol é de $442 \mathrm{~mm}$ com ciclo de 90 dias, valor médio diário de 4,9 mm e valor máximo chegando a $8,18 \mathrm{~mm}$, obtido na fase de floração.

O consórcio do girassol com feijão-caupi é apontado como vantajoso em alguns estudos. Em trabalho realizado por [18], em região semiárida, avaliou-se o desempenho produtivo de cultivares de girassol nesta região, quando cultivadas em monocultivo e em consórcio com feijão, observou-se que a cultivar $\mathrm{H} 251$, entre outras, alcançou rendimento acima da média geral e pode ser indicada para o cultivo de giras sol na região semiárida do Nordeste baiano, tanto para o monocultivo, como para o consórcio com o feijão.

Os resultados de produtividade ora encontrados são semelhantes a outros estudos desenvolvidos na região semiárida. [19], avaliando cultivares de girassol no Nordeste brasileiro, verificaram que no ano de 2008, o rendimento médio de grãos de algumas cultivares variaram de $1.415 \mathrm{~kg} \mathrm{ha}^{-1}$ a $1.931 \mathrm{~kg} \mathrm{ha}^{-1} \mathrm{com}$ média geral de $1.633 \mathrm{~kg} \mathrm{ha} \mathrm{ha}^{-1}$. Para [20] avaliaram as potencialidades do giras sol para cultivo no Semiárido nordestino e chegaram à conclusão de que o bom desempenho que o girassol vem apresentando nessas condições, até então, faz com que o mesmo seja mais uma alternativa de exploração comercial, principalmente para a agricultura familiar, estes autores observaram rendimentos médios de grãos das cultivares entre $1.532 \mathrm{~kg} \mathrm{ha}^{-1}$ e $2.791 \mathrm{~kg} \mathrm{ha}^{-1}$, com média geral superior a $2.100 \mathrm{~kg}$ $\mathrm{ha}^{-1}$, evidenciando o alto potencial para a produtividade do conjunto avaliado [21].

\section{CONCLUSÃO}

O cultivo do girassol consorciado com o feijão-caupi, em barragem subterrânea, com irrigação suplementar, apresenta produtividade inferior ao monocultivo do girassol.

\section{REFERÊNCIAS}

[1] Moura, M. S. B.; Galvincio, J. D.; Brito, L. T. L.; Souza, L. S. B.; Sá, I. I. S.; Silva, T. G. F. Clima e água de chuva no SemiÁrido. In: Brito, L. T. L.; Moura, M. S. B.; Gama, G. F. B. (Ed.). Potencialidades da água de chuva no Semi-Árido brasileiro. Petrolina: Embrapa Semi-Árido, 2007. cap. 2, p. 37-59.

[2] Silva, M.L.O.; Faria, M.A.; Morais, A.R.; Andrade, G.P.; Lima, E.M.C. Crescimento e produtividade do girassol cultivado na entressafra com diferentes lâminas de água. Revista Brasileira de Engenharia Agrícola e Ambiental, Campina Grande, v.11, n.5, p.482 - 488, 2007.
[3] Santos, M. O.; Freitas, I. M. de; Brito, L. T. de L.; Anjos, J B. dos. Barragem subterrânea: água para uso na agricultura. Niterói: Programa Rio Rural, 2009. 13 p. il. (Programa Rio Rural. Manual Técnico, 17).

[4] Porto, W.S.; Carvalho, C.G.P.; Pinto, R.J.B. Adaptabilidade e estabilidade como critérios para seleção de genótipos de girassol. Pesquisa Agropecuária Brasileira, Brasília, v.42, n.4, p.491-499, abr. 2007.

[5] Mourad, A. L. Principais culturas para obtenção de óleos vegetais combustíveis no Brasil. In: Encontro de energia no meio rural, 6. 2006, campinas. Anais... disponível em: $<$ http://www.proceedings.scielo.br/scielo.php?script=sci_arttex t\&pid=MSC0000000022006000200029\&lng=en\&nrm=abn>. Acessado em 17 de setembro de 2016.

[6] Thomaz, G. L. Zagonel, J.; Colasante, L. O.; Nogueira, R. R. Produção do girassol e teor de óleo nas sementes em diferentes épocas de semeadura no Centro-Sul do Paraná. Ciência Rural, v. 42, n. 2, p. 203-208, 2012.

[7] Souza, W. L.; Ferrari, R. A.; Scabio, A.; Barcaro, P Biodiesel de óleo de girassol e etanol. Biomassa \& Energia, v.2, n.1, p.1-5, 2005.

Г81 EMPRESA BRASILEIRA DE PESQUISA AGROFLESTAL. Atividades do Girassol. 2007.

[9] Ferreira, D, F. Sis var: a computer statistical analys is system. Ciência e Agrotecnologia, Lavras, v. 35, n. 6, p. 1.039-1.042, 2011.

[10] Bayu, W.; Addison, M.; tadesse, B.; Admassu, L. Intercropping Tef and sunflower in semi-arid areas of Welo, Ethiopia. Tropical Science, v. 47, p. 16-21, 2007.

[11] Vale. E. H.: Pinto. C. M.: Sizenando Filho. F. A.: PITOMBEIRA, J. B. Comportamento do girassol e feijão caupi cons orciados em série de subs tituição. Revista Verde de Agroecologia e Desenvolvimento Sustentável, v.6, n.2, p. 69-74, 2011.

[12] Silva, M. R.; Ungaro, M. R. G.; Ramos, N. P.; Aguiar, R. H. Cultivo de girassol em Lucianópolis - Estudo de caso In: Reunião Nacional de Pesquisa de Girassol, 16, e Simpósio Nacional sobre a Cultura do Girassol, 4, 2005, Londrina. Anais... Londrina: Embrapa Soja, 2005. p.68-70.

[131 JONER. G.: METZ. P. A.: ARBOITTE, M. Z.; PIZZUTI, L. A. D., BRONDANI, I. L.; RESTLE, J. Aspectos agronômicos e produtivos dos híbridos de girassol (Helianthus annuus L.) Helio 251 e Helio 360. Ciência Animal Brasileira, Goiânia, v.12, n.2, p. 266-273, 2011.

[141 ACOSTA. J. E. Consumo hídrico da cultura do girassol irrigada na região da Chapada do Apodi - RN. 2009. 73p. Dissertação (Mestrado em Agrometeorologia) - Universidade Federal de Campina Grande, Campina Grande, 2009. 
[15] CONAB. Companhia Nacional de Abastecimento. Acompanhamento da safra brasileira - grãos. Disponível em $\langle$ http:/www.conab.gov.br/OlalaCMS/uploads/arquivos/16_09_09_15_

18_32_boletim_12_setembro.pdf.>. Acessado em 19 de setembro de 2016 (v.3, safra 2015/16, n. 12).

[16] Castro, C.; Farias, J. R. B. Ecofisiologia do girassol. In: LEITE, R. M. V. B. C.; BRIGHENTI, A. M.; CASTRO, C. Girassol no Brasil. Londrina: Embrapa Soja, 2005. p. 163-218.

[17] Cavalcante Junior, E. G. Produção e necessidade hídrica da cultura do girassol irrigado na chapada do Apodi. 2011. 61f. Dissertação (Mestrado em Irrigação e Drenagem) - Universidade Federal Rural do Semi-Árido, Mos soró-RN, 2011.

[181 Junior. J. A. S.. Ghevi. H. R.. da Silva Dias. N.. Soares. F. A. L., \& Nobre, R. G. (2011). Doses de boro e água residuária na produção do girassol. Revista Ciência Agronômica, 42(4), 857864.

[19] W. L.; Oliveira, I. R.; Carvalho, C. G. P.; Lira, M. A.; Ferreira, F. M. B.; Tabosa, J. N.; Macedo, J. J. G.; Oliveira, E. A. S.; Feitosa, L. F.; Rodrigues, C. S.; Melo, K. E. O.; Menezes, A. F.; SantoS, M. L. Avaliação de cultivares de girassol no Nordeste brasileiro. Aracaju: Embrapa Tabuleiros Costeiros, 2010. 7p. (Embrapa Tabuleiros Costeiros. Comunicado Técnico, 106).

[20] lira, m. a.; carvalho, H. W. L.; Chagas, M. C. M.; Bristot, G.; Dantas, J. A.; Lima, J. M. P. Avaliação das potencialidades da cultura do girassol, como alternativa de cultivo no semiárido nordestino. Natal: EMPARN, 2011. 40 p. (EMPARN. Documentos, 40).

[21] Silva, M. S. L.; Mendonça, C. E. S.; AnjoS, J. B.; Honório, A. P. M.; Silva, A. S.; Brito, L. T. L. Barragem Subterrânea: água para produção de alimentos. In: Brito, L. T. L.; MourA, M. S. B.; Gama, G. F. B. (Ed.). Potencialidades da água de chuva no semi-árido brasileiro. Petrolina: Embrapa Semi-Árido, 2007. cap. 6 , p. 121-137. 